\title{
Cholangioscopy-assisted guidewire placement in post-liver transplant anastomotic biliary stricture: efficient and potentially also cost-effective
}

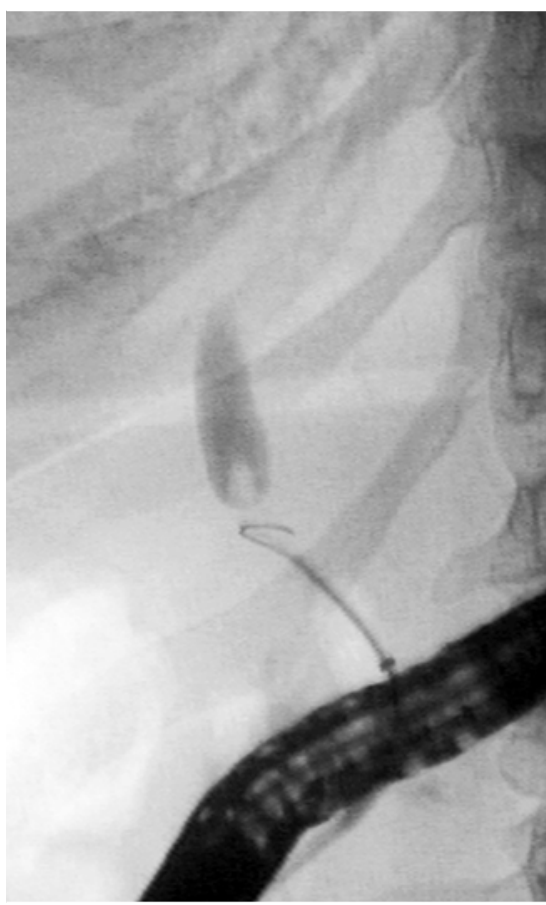

- Fig. 1 Failed attempt to pass a guidewire through an anastomotic biliary stricture under fluoroscopic guidance. The guidewire is looped in the distal bile duct, and is not progressing.

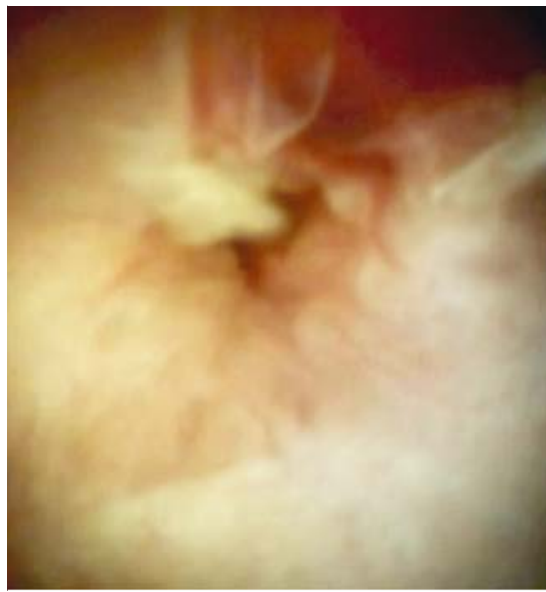

Fig. 2 Direct cholangioscopy revealing a narrow anastomotic biliary stricture.

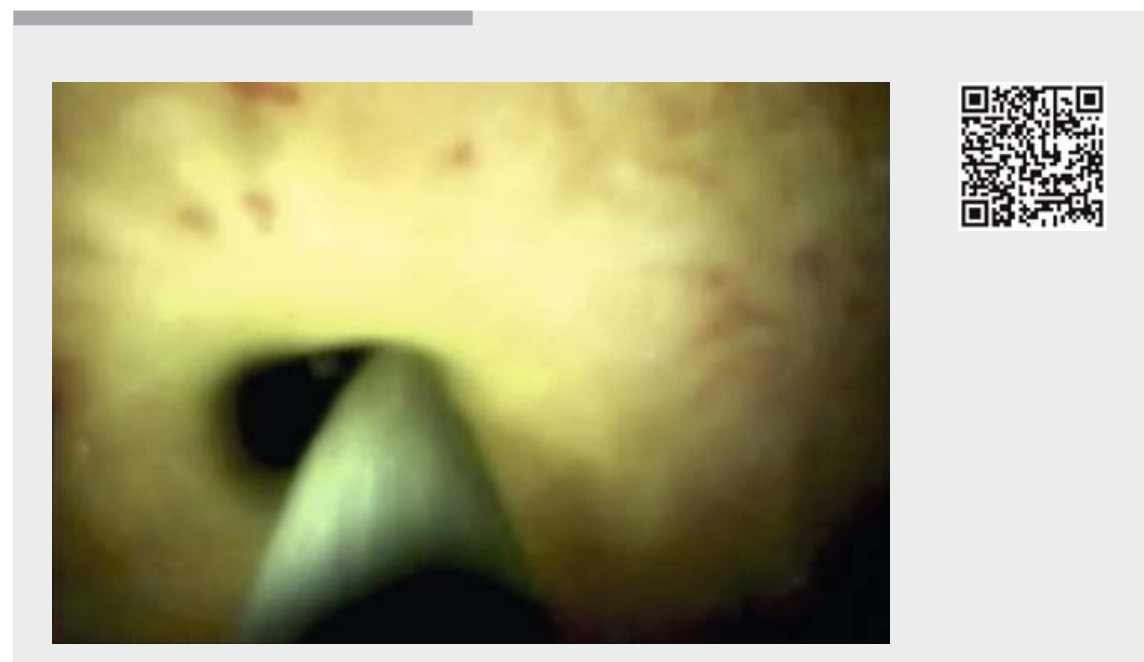

Video 1 Cholangioscopy-assisted guidewire placement in five patients with anastomotic biliary stricture following liver transplantation: passage of the stricture failed under fluoroscopic guidance, so the stricture orifice was identified by direct cholangioscopy and a guidewire was placed under direct visual guidance.

Endoscopy is the first-line therapy for most post-liver transplantation anastomotic biliary strictures. Passage of a guidewire through the stricture is done under fluoroscopic guidance. Although anastomotic biliary strictures are usually short, they can be tight, fibrotic, and angulated, sometimes not allowing guidewire passage. Additional interventions (percutaneous transhepatic cholangiography $[\mathrm{PTC}]$, or endoscopic ultrasoundguided biliary drainage [EUS-BD]) can be necessary to avoid re-operation.

The successful use of direct cholangioscopy to assist guidewire placement has been reported for strictures following liver transplantation from deceased and living donors [1,2], and for post-surgical [3] and malignant [4] strictures. However, no cost analysis has been conducted.

We present a video involving five postliver transplantation patients with anastomotic biliary stricture which could not be traversed by the guidewire, despite the use of different guidewires
( Fig. 1), occlusion balloons, and rotatable sphincterotome. Eventually, direct cholangioscopy (SpyGlass DS direct visualization system; Boston Scientific) was used. The stricture ( $\mathbf{F i g . 2}$ ) and orifices ( $>$ Fig. 3 , > Fig. 4 a) were clearly identified using the SpyScope. The guidewire was placed under direct visual

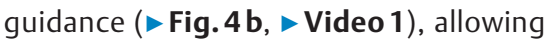
endoscopic retrograde therapy. There were no complications. PTC and EUS-BD were avoided in all cases.

Based on procedure and device costs at our institution, the cholangioscopy increased the median individual expense by US\$ 3545 . The costs of uneventful EUS-BD and PTC are estimated at US\$ 4065 and US\$9090, respectively. Considering that 100 liver transplants are performed yearly at our hospital, the incidence of anastomotic biliary stricture is $12 \%$ [5], and failure to traverse the stenosis occurs in $9 \%$ of patients with anastomotic biliary stricture, use of cholangioscopy would save from U\$ 6240 up to US\$ 66540 per year. These savings 


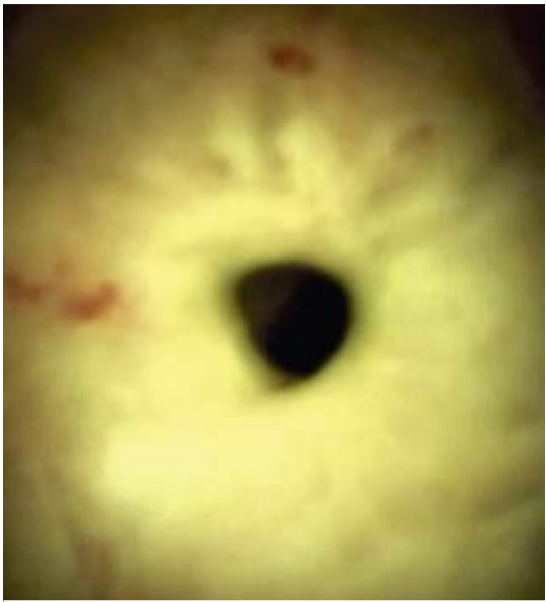

- Fig. 3 Orifice of an anastomotic biliary stricture in another patient, identified by direct cholangioscopy.

could be higher if the needs for differently skilled physicians, additional equipment, and time are considered. Moreover, the transpapillary drainage failure and morbidity rates for EUS-DB and PTC are not negligible. This case series confirmed that cholangioscopy-assisted guidewire placement is safe. Even though it is limited, this preliminary analysis suggests that use of cholangioscopy might be cost-effective when an anastomotic biliary stricture cannot be traversed using fluoroscopy. Further studies are necessary.

Endoscopy_UCTN_Code_CCL_1AZ_2AL

\section{Competing interests}

Dr. Angelo Paulo Ferrari is an independent consultant for Boston Scientific.

\section{The Authors}

Fernanda P. Martins, Angelo P. Ferrari Endoscopy Unit, Hospital Israelita Albert Einstein, São Paulo, SP, Brazil
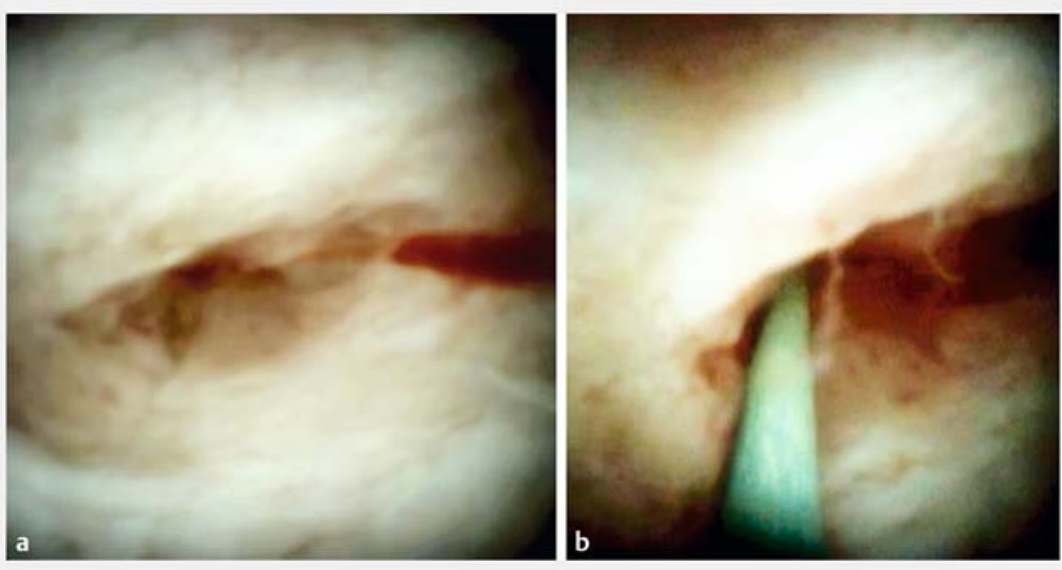

Fig. 4 Cholangioscopic view in a further patient. a Orifice of the anastomotic biliary stricture. $\mathbf{b}$ Passage of a guidewire through the stricture under direct visual guidance.

Corresponding author

\section{Fernanda P. Martins, MD, PhD}

Rua Barata Ribeiro, 490 cj 118, São Paulo 01308-000, Brazil

Fax: +55-11-38877997

fernandapbm@gmail.com

\section{References}

[1] Kumar S. Cholangioscopy-directed endoscopic intervention for post-liver transplantation anastomotic biliary stricture. Gastrointest Endosc 2015; 81: 1014-1015

[2] Woo YS, Lee JK, Noh DH et al. SpyGlass cholangioscopy-assisted guidewire placement for post-LDLT biliary strictures: a case series. Surg Endosc 2016; 30: 3897 - 3903

[3] Theodoropoulou A, Vardas E, Voudoukis E et al. SpyGlass Direct Visualization System facilitated management of iatrogenic biliary stricture: a novel approach in difficult cannulation. Endoscopy 2012: UCTN: 44 (Suppl. 02): E433-434

[4] Bhat YM, Kochman ML. Novel management of complex hilar biliary strictures with the Spyglass Direct Visualization System (with video). Gastrointest Endosc 2009; 69: $1182-1184$

[5] Martins FP, De Paulo GA, Conceição RD et al. Incidence, risk factors and ERCP outcome for biliary complications after cadaveric OLT. Hepatogastroenterology 2011; 58: 732 737

\section{Bibliography}

DOI https://doi.org/10.1055/s-0043-117940

Published online: 13.9.2017

Endoscopy 2017; 49: E283-E284

(c) Georg Thieme Verlag KG

Stuttgart · New York

ISSN 0013-726X

\section{ENDOSCOPY E-VIDEOS}

https://eref.thieme.de/e-videos

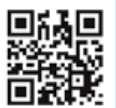

Endoscopy E-Videos is a free access online section, reporting on interesting cases and new

techniques in gastroenterological endoscopy. All papers include a high quality video and all contributions are freely accessible online.

This section has its own submission website at

https://mc.manuscriptcentral.com/e-videos 